\title{
Physiology in fine fettle in the fair city
}

\author{
K. D. O'Halloran ${ }^{1}$
}

Received: 30 August 2016/Accepted: 1 September 2016/Published online: 8 September 2016

(C) Royal Academy of Medicine in Ireland 2016

Dublin played host in late July to a joint meeting of The Physiological Society and American Physiological Society, a continuation of recent collaborative ventures between the two learned societies. The 4-day fiesta of physiology began with an early career event at the Royal College of Surgeons in Ireland, followed by the main meeting held at the Dublin Convention Centre, providing splendid summer views of the Liffey and the revamped docklands area of the capital. Twelve hundred scientists were in attendance from all over the globe ensuring a truly international celebration. The programme, packed with plenary and keynote lectures, symposia and workshops, and several hundred poster communications, offered opportunity-from novices to Nobel laureates-to share and discuss research findings across a broad spectrum of the discipline. Research symposia were further complemented with sessions focussed on education and outreach, ethics, research careers, and publication.

There was a very strong showing by local physiologists and biomedical scientists including participation and coordination of several symposia. Professor John F. Cryan, University College Cork, enthralled all with a fascinating account of gut microbes and the means by which they manipulate our mood and mind, amongst other matters-a plenary lecture that was open to members of the public. That lecture and several others from the meeting were livestreamed and are available to view on The Physiological Society's website (http://www.physoc.org).

The celebratory mood of the meeting reached a crescendo at a banquet held in the ballroom of the Hilton Doubletree Hotel, which catered for almost 500 guests. After dinner, speeches were sufficiently succinct to allow time for revellers to enjoy a Science Céilí. It is rumoured thereafter that many repaired to one or more of the city's established watering holes to sample local fare. Punctual attendance by most the next morning provided evidence of good discipline, or at the very least due diligence!

The success of the conference on the whole in part reveals the twenty-first century renaissance that physiology enjoys, now that the dust has settled in the post-genomic era. It is increasingly clear that physiology, the discipline that seeks to explore the very logic of life, is in good health. Physiology's pursuit of knowledge of fundamental form and function with its focus on integration at every level of organisation of the organism is proving pivotal in the quest to better understand human health and disease. The Dublin meeting suggests that Physiology is assured of a bright future for many summers to come.
K. D. O'Halloran

K.OHalloran@ucc.ie

1 Department of Physiology, University College Cork, Cork, Ireland 